
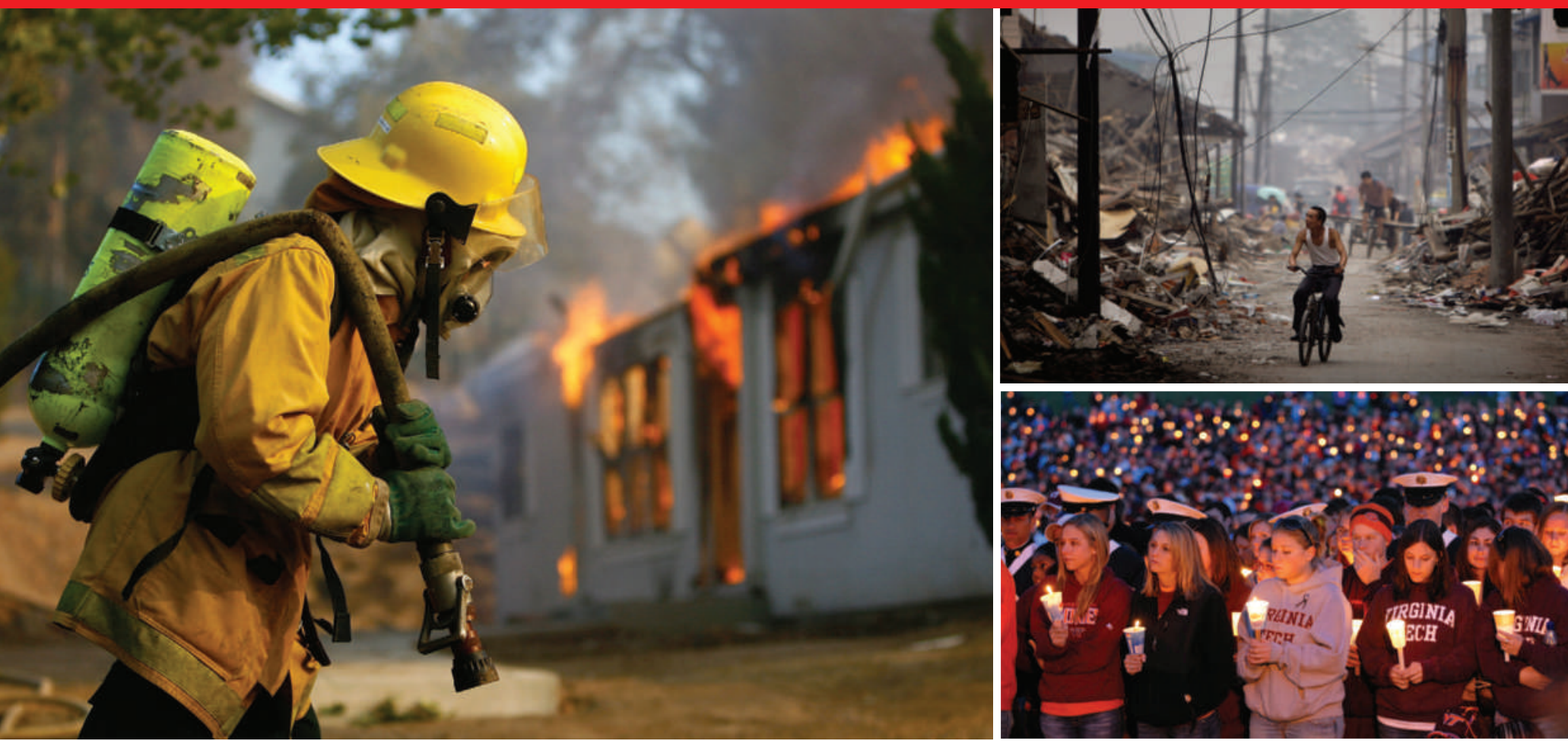

\title{
Crisis communication
}

\section{Messages appear on Internet-based social networks within minutes of disasters occurring.} Lea Winerman investigates how to harness this trend to create official community-response grids.

T he messages began to fly almost as soon as the bullets stopped. Starting at 7:00 on the morning of 16 April 2007, an undergraduate named Seung-Hui Cho had carried a pair of semi-automatic pistols through the campus of the Virginia Polytechnic Institute and State University in Blacksburg - better known as Virginia Tech - gunning down dozens of students and professors as he went. By 9:51 it was over: Cho had turned one of his guns on himself. But the survivors, lacking any official word from the university other than the total death toll, were still in the dark about which of their friends had lived or died. So they turned to the best information source they had: the Internet - notably, the social website Facebook.

Posts appeared in quick succession, indicating the names of suspected casualties. Those here have been edited for privacy reasons. " $\mathrm{CH}$, as reported by a sorority sister," read a post on one Facebook page. "I just finished speaking with his girlfriend, and it appears JH is a fatality as well," read another post. As the information accumulated, the participants spontaneously began to develop their own norms to ensure accuracy. Anonymous or vague posters were asked for clarification. People had to identify themselves when they put forward the name of a shooting victim, for example, and explain where they had got the information.

By the time the university released the names one day later, it was old news to the online community: they had identified all 32 of the deceased already.

The Virginia Tech story is hardly unique. "When people are under threat, perceived or actual, they go into this intensified informationseeking period," explains Leysia Palen, a computer scientist at the University of Colorado, Boulder. And these days, they are increasingly doing so through social networking sites.

But social-network users often end up bypassing the authorities - a tendency that has left officials scrambling to use this information and integrate it into traditional responses.

"Emergency managers have this desire to control the flow of information," says Jeannette Sutton, a sociologist who also studies disaster communication at the University of Colorado. "But you can't control it. The best we'll be able to do is figure out how to harness it."

Palen calls her research 'crisis informatics', and it has taken her to several disaster hotspots. In the Virginia Tech case, for example, she and her colleagues began monitoring websites within hours of the shooting, then travelled to Blacksburg five days later to interview people. Back in Colorado, they created a detailed timeline of official communications (university e-mails, press conferences) and unofficial communications (Facebook messages, Flickr photos) that stretched across a giant whitepaper diagram on their office wall.

This allowed them to track the emergence of those informal norms. "One of the concerns from the emergency-management point of view is 'how can we know the information [posted on websites] is accurate?"” Palen says. "We saw that here it was self-correcting."

\section{Spreading like wildfire}

In October and November 2007, Palen and her colleagues examined the online response to another crisis. During that time, more than 20 wildfires raged from Santa Barbara to San Diego counties in southern California, eventually burning 200,000 hectares, destroying about 1,500 homes and forcing many more households to evacuate.

Palen and her colleagues monitored local news websites and online forums including Craigslist, Facebook, Twitter and Flickr. By the tenth day of the fires, they also began to survey and interview area residents.

"National news websites were completely worthless as they ignored everything except the comparatively minor Malibu fire that burned near some celebrity homes," one evacuee wrote.

And official government communications, although sometimes useful, couldn't be relied 
z on either. "The county so-called emergency site was always crashed," another wrote.

Instead, many people turned to websites run by local media, such as the National Public Radio station KPBS, based in San Diego, or by individuals. On these sites, the updates came from any local resident with an Internet connection and information to share. Some hosted Google maps on which users could overlay information such as the location of the fires. Others hosted discussion boards on which people who hadn't evacuated, or who had made it back to their homes, could share what they were seeing.

\section{Worldwide webs}

Online information-sharing during crises isn't limited to the United States, and other media agencies are already using the concept. In early January, for example, Al Jazeera, a satellite television network headquartered in Doha, Qatar, launched an experimental website that aggregates text messages, mobile-phone reports and Twitter feeds about the conflict in the Gaza Strip on a Microsoft Virtual Earth map (http://labs.aljazeera.net/warongaza).

And Yan Qu, Philip Wu and Xiaoqing Wang, researchers at the University of Maryland in College Park, observed information-sharing trends after the 12 May 2008 earthquake in China's Sichuan province.

"The earthquake happened at 14:28. Within one minute there was a message posted on a Tianya forum," says Wu. Tianya is one of China's most popular websites - a bulletinboard system with more than 20 million registered users. Within 10 minutes, 56 discussion threads reported feeling the earthquake in 22 cities throughout the region.

The researchers read and classified the thousands of threads that appeared on the site in the days following the quake.

They found that Chinese citizens used the site for many of the same purposes as Californians did during the wildfires: seeking information about their homes, hometowns and family, and coordinating action to help victims of the crisis. And there were some widely reported success stories. In one, a college student saw news reports about the military having a difficult time finding a spot to land a rescue helicopter near a destroyed village in the mountains. The woman, who had grown up in the area, posted a detailed description of a potential landing spot in an online forum, and begged users to forward it to authorities. The post eventually found its way to the military, who landed a helicopter in the spot she described.

Unfortunately, says $\mathrm{Wu}$, that kind of story is rare. In general, professional emergency responders are only vaguely aware of how citizens use social media during disasters. "Even in the United States, professional emergency responders are just beginning to think about this. In China I don't think there's any kind of explicit effort," he says.

It's the lack of official involvement that Ben Shneiderman, a computer-science professor at the University of Maryland and his wife Jennifer Preece, dean of the university's College of Information Studies, are trying to change.

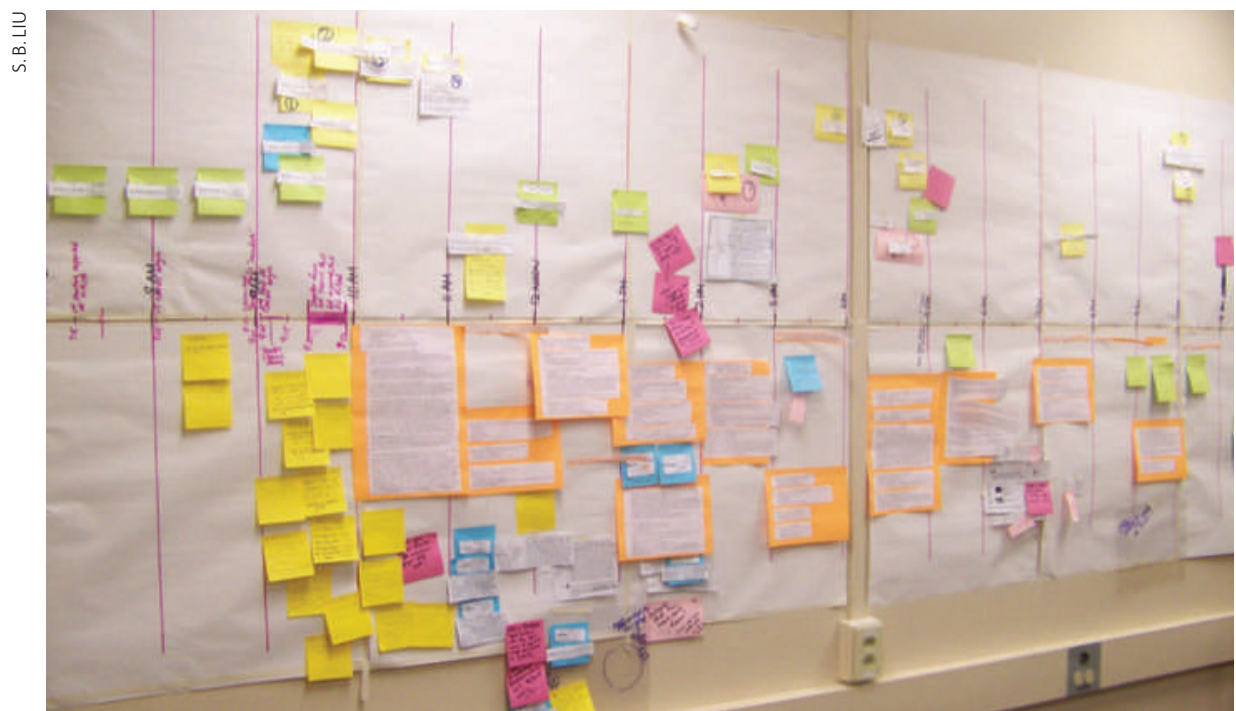

Researchers tracked social norms in the communications following the Virginia Tech shootings in 2007.

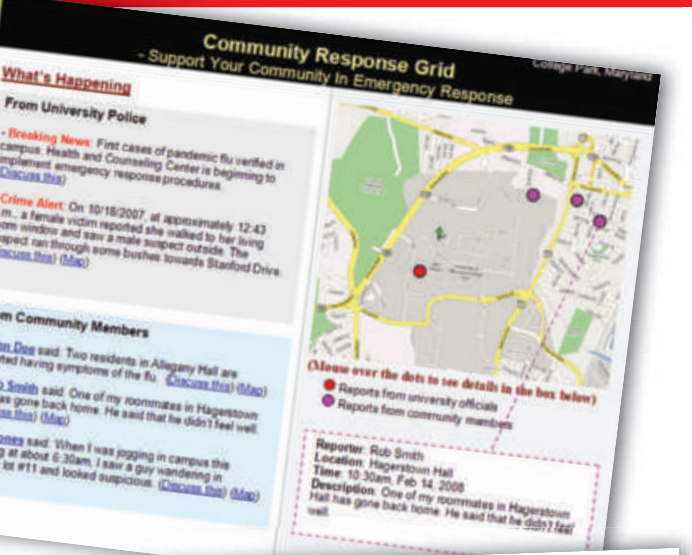

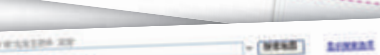

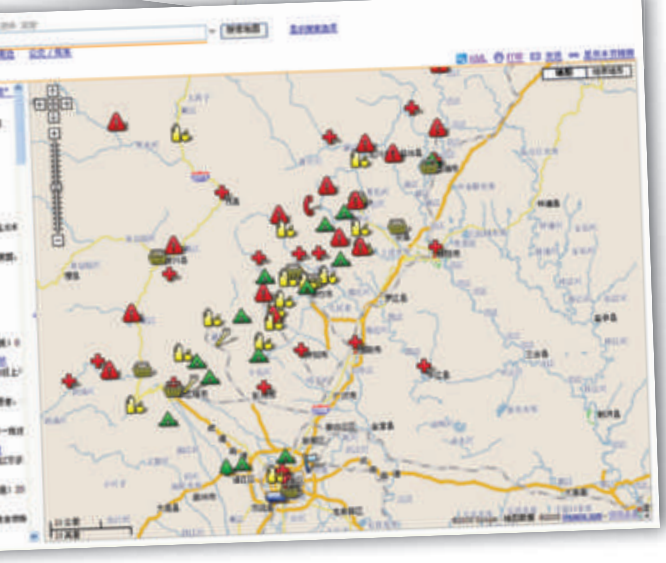

Community response grids (top) integrate official responses with information from the public, such as this Google map created by Chinese citizens during the Sichuan quake in 2008.

In 2007, they published a one-page article in Science called '911.gov' (B. Shneiderman and J. Preece Science 315, 944; 2007). Taking their title from the emergency telephone number for much of North America, they envisioned a web-based 'community response grid' that would combine the power of social networking sites with official government emergencyresponse systems.

An emergency telephone system works terrifically under normal circumstances, says Shneiderman. "But when you get a Hurricane Katrina or a 9/11, [the call centres] become overwhelmed." Potentially, at least, a website can handle such sudden surges more gracefully by tapping more servers as needed.

As Shneiderman sees it, people would report incidents via the Internet or by sending text messages from their mobile phone rather than by calling 911 . Software would aggregate those reports into a constantly updated map of the situation, which citizens and emergency responders could check without encountering clogged phone lines. People could also register to receive block-by-block information - again via e-mail or text message - about whether to stay in place, to evacuate or to respond in some other way. And people would be able to coordinate with their neighbours before, during and after emergencies on community message boards. So, for example, a family could agree to take responsibility for a wheelchair-bound neighbour during an evacuation. 


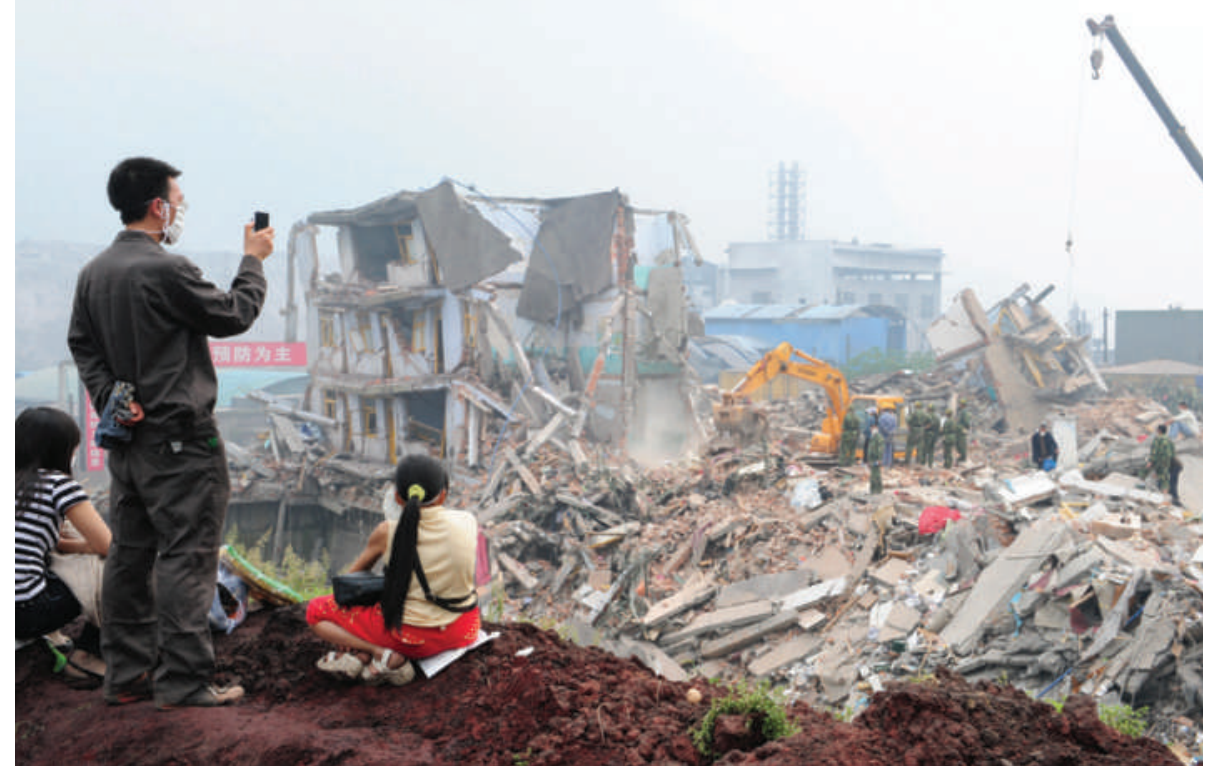

Mobile-phone photos of the Sichuan earthquake in China aided the rescue efforts.

Shneiderman is collaborating with $\mathrm{Wu}$, $\mathrm{Qu}$ and others to explore how a small-scale version of the system would work on the University of Maryland campus. Wu says that the official emergency responders in the university Department of Public Safety are very interested in the idea - but they are also wary. They are concerned that they wouldn't have the staff to run the system, he says, and that it might confuse people who are already well-trained to call 911 in an emergency. Then there's the possibility that people could use the system to spread bogus information and rumours. "If you have everybody able to do peer-to-peer, then there is widespread panic," one safety officer told the researchers.

That reaction - interest tinged with scepticism - mirrors the reaction of many professional emergency responders.

Federal and local disaster-response agencies have long operated under the Incident Command System, a standardized protocol developed in the 1970s by firefighters battling California wildfires, and later adopted by federal agencies including the Federal Emergency Management Agency (FEMA).

The system, with a clear, top-down chain of command, views communication with the public as a one-way street: information is supposed to flow from officials to the public via warnings sent out over $\mathrm{TV}$, radio and other media. That view fits well with older academic research in disaster sociology.

"Thirty years ago no one talked about crisis communication," says Dennis Wenger, a sociologist at the National Science Foundation who has studied disasters for more than three decades. "Back then the term was warnings research."

The questions that preoccupied researchers then were how to write an effective warning - instructing people to evacuate before a hurricane, for example - and how best to make sure everyone heard it.

"But then all of a sudden came the Internet revolution, and it blew apart this notion of a linear chain," says sociologist Kathleen Tierney, director of the Natural Hazards Center at the University of Colorado. Social-networking and photo-sharing sites, mobile phones and text messages have turned the chain into a web.

In hindsight, that was only to be expected. The chain was never as linear as the models made it out to be. One of the first to realize that was Thomas Drabek, a disaster researcher at the University of Denver, Colorado, who surveyed evacuees after the South Platte River flooded near Denver in 1965. More than 60\% of the people he spoke to told him that even after they received a warning telling them to evacuate, they tried to confirm it - checking with family and friends, talking things over, watching to see what their neighbours were doing - before taking action.

\section{Reaching an understanding}

Researchers have observed the same information-sharing inclination in many disasters since. After the bombing of the World Trade Center in New York in 1993, Benigno Aguirre, a sociologist at the Disaster Research Center of the University of Delaware in Newark, found that people who were in large offices took longer to evacuate than people who were in smaller groups, because it took them longer to come to a common understanding of what was happening.

"It is actually very difficult to get human beings to percive that they are at risk," says Dennis Mileti, a disaster-management researcher at the University of Colorado. "How do you convince people that they are at risk? Only through other people." And there, as long as the process isn't too time-consuming, is one of the advantages of the Internet. "Long before technology, you could check in with neighbours next door," says Sutton. "But now you can check in with peers around the country."

Garry Briese - a regional administrator for FEMA in Denver and, for 22 years before that, the executive director of the International Association of Fire Chiefs - is excited about the opportunity that public feedback offers. He recounts the example of a wildfire in Deckers, Colorado, last summer, when he was able to find photos of the fire posted online by local residents within 30 minutes of hearing about the fire himself.

"It expands our ability to have situational awareness," he says. "Someday, in a fast-moving wildfire, if we had the right system, we could ask people by a text alert to take pictures and send them to an emergency centre. And our ability to understand what the scene looks like would be enhanced."

That scenario is still a long way from reality, says Briese, who, in July 2008, talked to an official from a large city's emergency operations centre about the information already available on the web. "A few days later, the guy called me and said 'you know, my IT department has me blocked from those sites," he says. "So here we have an emergency manager who wants to learn, and the first thing he has to do is go to the IT department and convince them."

Sutton encountered something similar when she spoke about her research at a conference of state-level emergency managers in September 2008. "I had a couple of people say to me, 'This is so new to us, we don't even know what to ask", she says.

In any case, answers might not have been easy to supply. "This information is out there, and you can find it online," Sutton says. "But how do you aggregate it, and where would it get plugged into? Would it go back to an emergency operations centre, a joint information centre, a public information office?"

When Shneiderman proposed community response grids in 2007, he thought that it might become a reality within $3-5$ years. Now, with so much research still to do, he thinks 5-10 years might be more accurate. But he is used to waiting. He helped to develop the concept of hypertext links in the 1980s and saw them become integral to the web more than a decade later.

Not everyone has Internet access or the technical knowhow to take advantage of it. But, during a disaster, a communityresponse grid could benefit almost everyone, as family, friends, neighbours and authorities share what they know. "I think this is inevitable," says Shneiderman.

Lea Winerman is science editor for The Online NewsHour with Jim Lehrer. 